Резюмируя изложенное, следует заметить следующее:

во-первых, фактор участия сотрудников ОВД в процессе сетевого обмена корреспондирует осознанию ими особой значимости демонстрации заповедей цифровой бдительности;

во-вторых, неосмотрительное пользование сотрудниками потенциалом Интернет-сети подрывает имидж системы МВД России и наносит ущерб репутации самим сотрудникам;

в-третьих, адекватность реагирования на угрозы и вызовы внедрения в практику современной коммуникации новых технологий предопределяется своевременным применением соответствующих норм правового регулирования области защиты персональных данных сотрудников ОВД, знанием каждым сотрудником действующих нормативных положений в отмеченной области и и его осознанным отношением к их безусловному соблюдению.

$$
* * *
$$

1. Методические рекомендации МВД России от 13 марта 2020 г. № 1 / 2704 «О правилах поведения и организационной защите персональных данных сотрудников органов внутренних дел Российской Федерации и их близких в сети «Интернет» (данный документ официально опубликован не был). 2020. $-17 \mathrm{c}$.

2. Памятка для сотрудников государственных органов и учреждений с государственным участием по работе в сети Интернет, в том числе в социальных сетях и на блог-платформах. - URL: http://bap.prokuror.gov.kz/rus/glavnaya-voennaya-prokuratura/pamyatka-dlya-sotrudnikovgosudarstvennyh-organov-i-uchrezhdeniy-s (дата обращения: 03.01.2021)

3. Приказ МВД России от 26 июня 2020 г. № 460 «Об утверждении Кодекса этики и служебного поведения сотрудников органов внутренних дел Российской Федерации». - URL: https://media.mvd.ru/files/application/1915512 (дата обращения: 03.01.2021)

4. Приказ МВД России от 16 июня 2011 г. № 683 «Об утверждении Положения об Управлении по взаимодействию с институтами гражданского общества и средствами массовой информации Министерства внутренних дел Российской Федерации» // СПС КонсультантПлюс

5. Романчева Н.И. Базовые Интернет-технологии. Учебное пособие - М.: МТУ ГА, 2008. - 96 с.

6. Чимаров С.Ю. Правовые основы работы сотрудников органов внутренних дел с социальными медиа // Тенденции развития науки и образования. - 2020. - № 60. - Часть 6. - С. 5-8.

7. Social Media Guidance. A guide for police officers and police staff. January 2014. - 24 p. - URL: http://istmat.info/node/27762 (дата обращения: 12.01.2021)

\title{
Чимаров С.Ю. \\ Некоторые аспекты воспитательной работы по минимизации эффекта профессиональной деформации личности сотрудника органов внутренних дел
}

Санкт-Петербургский университет МВД России (Россия, Санкт-Петербург)

doi: $10.18411 / l j-02-2021-177$

idsp: ljournal-02-2021-177

\section{Аннотация}

В статье представлен анализ отдельных аспектов профессиональной деформации личности сотрудника органов внутренних дел, включая ее разновидность, обусловленную переходом личности в «туннель реальности». Уточняя содержание феномена «туннель реальности», автор акцентирует внимание на важности учета в воспитательной работе многогранности проявления профессиональной деформации личности и необходимости целенаправленной работы по организации индивидуальной работы с каждым сотрудником в современных условиях, включая фактор тотального вовлечения человека в формат сетевого пространства.

Ключевые слова: воспитание, система воспитания, профессиональная деформация личности, сотрудник органов внутренних дел, межличностная коммуникация, коммодификация, цифровая бдительность. 


\section{Abstract}

The article presents an analysis of certain aspects of the professional deformation of the personality of an employee of the internal affairs bodies, including its variety, due to the transition of the personality into the "tunnel of reality". Clarifying the content of the reality tunnel phenomenon, the author focuses on the importance of taking into account in educational work the multifaceted manifestation of professional personality deformation and the need for purposeful work to organize individual work with each employee in modern conditions, including the factor of total human involvement in the format of the network space.

Keywords: upbringing, upbringing system, professional personality deformation, employee of internal affairs bodies, interpersonal communication, commodification, digital vigilance.

Фактор длительного выполнения представителями конкретного вида профессиональной деятельности неотделим от феномена профессиональной деформации личности, проявляемой в изменении таких ее качеств как: стереотипы восприятия, ценностные ориентации, характер, способы общения и поведения. Крайняя форма профессиональной деформации личности, как правило, выражается в формальном и исключительно функциональном отношении к окружающим ее людям. Согласно многочисленным наблюдениям и выводам психологов и педагогов, наиболее высокий уровень профессиональной деформации личности наблюдается $\mathrm{y}$ представителей так называемого «силового блока», включая сотрудников правоохранительных органов. Особенности служебной деятельности сотрудников органов внутренних дел (далее-ОВД) предопределяют важность воспитательной работы в направлении преодоления их выгорания и профессиональной деформации личности. Указанный тезис подкрепляется особенностями сетевого обмена с опорой на потенциал сети «Интернет». В этой связи следует согласиться с выводом С.А. Дементьева, отметившего, что трансформация реальной человеческой экзистенция в виртуальную ее форму порождает высокую степень зависимости от виртуализации и способствует возникновению угрозы потери реального человеческого бытия, самобытности сознания, персонального и социального опыта личностного интеллектуального потенциала и выступает в качестве предпосылки к угрозе информационной безопасности личности [1, с. 81]. Динамика интегрирования в область современной межличностной коммуникации и воздействие на пользователей из числа сотрудников эффекта коммодификации свидетельствуют об актуальности обращения к теме виртуального сознания вообще и учету возможности перевода личности сотрудника в «туннель реальности», в частности. Следует заметить, что под коммодификацией (от англ. «commodity»-товар для обмена) понимается процесс превращения товара, услуги, идеи или отдельной личности в новый товар или объект торговли. Согласно направлению нашего исследования, в качестве товара выступает все то, что предназначено для обмена. Исходя из логики учения о коммодификации и сообразно выводам отдельных исследователей предметной области «новых медиа», в номинацию товара следует включить цифровой контент популярных социальных сетей, мессенджеров, видео-хостинга и т.п. [4, с. 108]. Чрезмерная увлеченность отдельных сотрудников процессом самопрезентации свой личности и потенциала своих возможностей в сетевом пространстве несомненно может быть отнесено к разновидности профессиональной деформации личности, основанной на подчеркивании своей «возвышенности» над рядовыми гражданами, в силу своей «необычной» профессиональной принадлежности. Уход сотрудника в «туннель реальности» соответствует представлениям отдельных людей об особой миссии онлайн-технологий и осознанию ими необходимости приобретения от других сетевых пользователей «лайков» (англ. «Like»-нравиться) как свидетельства адекватной оценки 
своей профессиональной деятельности и благоприятного восприятия своих фото - и видео-изображений в форменном обмундировании, с оружием в руках и т.п.

Понятие «туннель реальности» (англ. «reality tunnel) впервые было введено в научный оборот американским писателем и психологом Т. Лири, специалистом в области психологии самоактуализации, личностного роста и группового взаимодействия. В дальнейшем, идеи Т. Лири были презентованы в книге Э. Берна «Люди, которые играют в игры. Игры, в которые играют люди» [5]. Еще в 1957 г. Т. Лири создал психодиагностическую методику, известную как «тест межличностных отношений Лири» («тест Лири»), и которую до сих пор используют спецслужбы США [2]. Апеллируя к термину «туннель реальности», представляется необходимым раскрыть его содержание. В понимании Т. Лири, «туннель реальности» суть индивидуальное и почти полностью бессознательное представление о мире. Основу такого представления составляет фактор восприятия сознанием человека лингвистических конструкций и совокупности символов. При этом символическая область может быть представлена музыкой, системой общественных паттернов поведения, принятых в обществе норм морали, совокупности полученных человеком знаний и др. Вместе с тем, важно учитывать, что «туннель реальности» тождественен «кривому зеркалу» истинной реальности и в этом смысле он подобен «пещере Платона». Утилитарное значение «туннеля реальности» заключается в обеспечении личности комфортного и безопасного бытия человека в окружающем его социуме. Осознание «туннеля реальности» в виде персональной модели восприятия реального мира не исключает искажения его подлинной картины. Другими словами, переход человека в «туннель реальности» и его длительное нахождение в этом «туннеле» являются результатом воспитания и обучения человека на конкретных образцах культуры и поведения других людей, являющихся для данного человека эталонными. В психологии указанное явление именуется запечатление или импринтинг (от англ. «imprint» - оставлять след) и сопровождается закреплением в памяти человека признаков объектов при формировании или коррекции врожденных поведенческих актов. С психологической точки зрения, методологическим основанием минимизации эффекта профессиональной деформации сотрудников ОВД могут служить выводы Э.Фромма, выделившего три психологических ресурса, способствующих преодолению личностью сложных жизненных ситуаций: во-первых, надежда-психологическая категория, способствующая проявлению оптимизма, поиску оптимальных решений и профессиональному росту; во-вторых, рациональная вера-твердая убежденность в наличии выхода из любой жизненной ситуации и необходимости анализа человеком своих ошибок, способствующего прогнозированию своих перспектив и стратегии поведения; в-третьих, «душевная сила-способность сопротивляться попыткам подвергнуть опасности надежду и веру» [3, с. 29].

Парадигма поведения окружающих каждого сотрудника ОВД коллег и специфика общения с определенным контингентом граждан несомненно способствуют его нахождению в определенном «туннеле реальности», границы и лабиринты которого существенно деформируется под эвентуальным воздействием массива деструктивной информации, циркулирующей в том числе и в процессе сетевого обмена. Изложенное позволяет сформулировать некоторые выводы.

Bo-nервblx, профессиональная деформация личности сотрудника органов внутренних дел заключается в ее психологической дезориентации, обусловленной постоянным давлением на нее как внешних, так и внутренних факторов. Конкретным проявлением отмеченной деформации личности выступают элементы агрессивности ее поведения, неадекватности в восприятии окружающих ее людей и конкретных ситуаций, а также утрата личностью интереса к результатам своей деятельности и к жизни в целом. Отмеченное порождает неспособность личности к своему эффективному самосовершенствованию и развитию. 
Bo-вторых, фактор пребывания сотрудника ОВД в «туннеле реальности» необратим и приемлем для любого профессионального сообщества.

$B$-mpeтьих, формат и «наполнение» отмеченного «туннеля» символическими единицами служебного бытия должны выступать в качестве предмета особого внимания со стороны руководящего состава, воспитательных структур и специальных служб, проводящих мониторинг «Интернет»-пространства.

$B$-четвертых, признавая позитивный ход развития информационного общества XXI в. и несомненное значение новых технологий цифрового общения, при организации воспитательной работы с сотрудниками ОВД следует проводить целенаправленную работу по недопущению ими необдуманных цифровых следов и бдительному восприятию контента получаемой цифровой информации.

$B$-nятыx, минимизации эффекта профессиональной деформации личности сотрудника ОВД в значительной степени способствует постоянное внимание начальствующих лиц, работников воспитательных, кадровых и психологических служб на различные проявления деструктивного поведения сотрудников, пренебрежительного отношения им исполнения своим служебных обязанностей, грубость и бестактность, допускаемых отдельными сотрудниками в отношении как сослуживцев, так и рядовых граждан, а также соблюдение сотрудниками предписаний цифровой бдительности, закрепленных в новой редакции Кодекса этики и служебного поведения сотрудников органов внутренних дел. Отмеченное безусловно занимает одно из приоритетных направлений в многогранной системе профилактической воспитательной работы с каждым сотрудником ОВД, ориентированной на блокировку подсознательной и бесконтрольно развивающейся социально-психологической деформации личности сотрудника.

$$
* * *
$$

1. Дементьев С.А. Реальность виртуальной модели в информационном обществе: риски и угрозы человеческой экзистенции // Вестник Адыгейского университета. Серия 1. Регионоведение. 2017. - № 1 (194). - С. 81-87.

2. Тест Лири. Диагностика межличностных отношений (ДМО). - URL: https://hr-portal.ru/tool/test-liridiagnostika-mezhlichnostnyh-otnosheniy-dmo (дата обращения: 05.01.2021)

3. Фромм Э. Революция надежды. - М.: Айрис-Пресс, 2005. - 352 с.

4. Чимаров С.Ю., Алексеев А.А. Правовые основы цифровой бдительности сотрудников органов внутренних дел Российской Федерации в условиях сетевой коммодификации // Вестник СанктПетербургской юридической академии. - 2020. - № 3 (48). - С. 107-112.

5. Berne E. Games People Play. What Do You Say After You Say Hello. - New York: Grove Press, 1972. $457 \mathrm{p}$.

\section{Чимаров С.Ю.}

Традиции и ритуалы как сущностной компонент воспитательной работы с личным составом органов внутренних дел Российской Федерации

Санкт-Петербургский университет МВД России (Россия, Санкт-Петербург)

doi: $10.18411 / l j-02-2021-178$

idsp: ljournal-02-2021-178

\section{Аннотация}

В статье представлен анализ отдельных воззрений научной мысли на определение понятий традиции и ритуалы. Выявляя сущностное предназначение традиций и ритуалов, наполняющих воспитательным смыслом всю область служебной деятельности личного состава органов внутренних дел, автор акцентирует внимание на их особой роли при решении многоплановых задач правоохранительной 